and contour changes are well demonstrated as, for example, in fractures and radiology of the gastrointestinal tract with contrast media, but the method is inadequate if an attempt is made to differentiate between varying densities and complex shadows, particularly in the chapters on diseases of the chest and in some of the illustrations of bone tumours and bone and joint diseases.

It is difficult to cover such a wide subject in a short volume, so that the book can be regarded only as an outline of X-ray interpretation. The basic principles are well covered, however, and the standard of production is what we have come to expect from the Oxford University Press.

R.E.S.

\section{FELLOWSHIP EXAMINATION PAPERS \\ for Diplomas of the Royal College of Surgeons,} Edinburgh, r947-5I

Pp. vii + 50. Edinburgh: E. \& S. Livingstone. I 95 I. 5s. $6 \mathrm{~d}$.

An invaluable collection of the papers of the past five years, sine qua non for all Fellowship candidates and their tutors.

\section{THE CARE OF THE AGEING AND CHRONIC} SICK

By A. P. Thomson, M.C., M.D., Ch.B., F.R.C.P., C. R. Lowe, M.D., CH.B., M.R.C.S., L.R.C.P., D.P.H., and Thomas McKeown, B.A., Ph.D., D.PhIL., M.D., M.B., B.S. Pp. 133. Edinburgh: E. \& S. Livingstone. 195I. 7s. 6d.

This well-produced paper-covered book reprints in convenient form seven papers of outstanding importance to workers in the field of geriatrics, as well as an extract from the Proceedings of the Royal Society of Medicine (1950) on the same subject. The papers comprise Professor Thomson's Lumleian lectures for 1949, and five papers by $\mathrm{Dr}$. C. R. Lowe and Professor McKeown, the latter reprinted from the British Fournal of Social Medicine and the British Medical Fournal. To this symposium, Professor Thomson adds a valuable preface.

Professor Thomson's Lumleian lectures are a brilliant and scholarly contribution to the understanding of the whole problem of the care of the aged, both in and out of hospital. They should be looked on as a ' must ' by every serious worker in the clinical and administrative field. The contributions of Drs. Lowe and McKeown, valuable as they are to the clinician, are of fundamental importance to all long-term planners in every field of medicine.

The picture they draw of a hospital of over a thousand patients, of whom 46 per cent. were incontinent and well over 90 per cent . bed-ridden, is a truly appalling one, smacking as it does of the 18th rather than the 2oth century. The mental apathy and 'subtle disintegration of human personality ' (in Professor Thomson's own words) adds to the gloom of the picture. From this picture they draw the heartening conclusions (implicit or ex- pressed) that the bulk of such patients should be capable of being rehabilitated, if handled early,

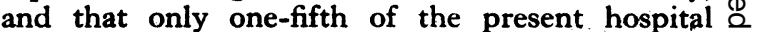
' chronic sick' population require general hospital $C$. treatment at all. This offers a firm statistical basis $\overrightarrow{\vec{F}}$ for the experience of workers in smaller fields. Not $\stackrel{S}{?}$ the least interesting part of the survey was that of $\bar{C}$ 393 patients on the waiting list, only 40 per cent. 음 were thought to merit admission to the hospital for the chronic sick. This emphasizes the importance of 'screening' waiting lists by domiciliary visits. Part of the value of this work lies in the ' human approach.' Some of Thomson's closing $\vec{\circ}$ words (p. 1 30), 'Our task is to learn how to give vitality and significance to the later years of human life,' are applicable to every doctor.

The authors are to be warmly congratulated on their work and the Birmingham Regional Hospital $\exists$ Board for sponsoring it.

T.N.R.

\section{ORAL AND DENTAL DISEASES}

By Hubert H. Stones, M.D., M.D.S., F.D.S.R.C.S. 2nd Edition. Pp. xix $+1,012$, d with 1,050 illustrations, 91 in colour. Edin- 음 burgh: E. \& S. Livingstone Ltd. 1951. \&5. -

A large printing of the first edition having been quickly exhausted, Professor Stones has had the opportunity of presenting a second edition fulle revised and in parts rewritten. He has incor 2 porated the results of further research work be $\vec{\theta}$ himself and others, and a new section on diseases. on of the muscles and of the nervous system appears? As in the case of the first edition, the author is to be congratulated on his immense task which is well produced and eminently readable.

The interest of the medical practitioner might well be engaged in particular in the chapters dealing with dental caries. The problems involved are fully set out and discussed, particularly as to whether the cause of the disease is initially either on acidogenic or a proteolytic process. A feature of these chapters and indeed of the whole work is that no likely theory is ignored although proper development is given to those ideas which by experience have proved themselves more acceptable. The non-dental reader need have no fear of becoming involved in matters which are the province only of the dental surgeon, operative dentistry being discussed only with regard to its effect on the dental tissues. The whole work is concerned with diseases and injuries of the mouth more particu- $D$ larly from the point of view of their aetiology, histopathology and clinical appearances.

As a reference book its value is enhanced by the $\sigma$ number of illustrations, many in colour, which $N$ bring out the points made in the text. For student $\mathrm{N}$ and practitioner these illustrations will be of con- $O$ siderable value as an aid to diagnosis of the less frequently seen conditions in and around the oral $\leftrightarrow$ cavity. For those studying for a higher qualifica- $\mathbb{D}$ tion or engaged in research the book is of inexhaustible value in itself, as well as for the lists of $\underline{T}$ references at the end of each chapter which act as 